\title{
A PRODUÇÃO CIENTÍFICA SOBRE AS TEORIAS NA ADMINISTRAÇÃO PÚBLICA BRASILEIRA: UMA ANÁLISE DOS PERIÓDICOS NO PERÍODO DE 2006 A 2017
}

\author{
THE SCIENTIFIC PRODUCTION ABOUT THE THEORIES IN THE BRAZILIAN PUBLIC \\ ADMINISTRATION: AN ANALYSIS OF THE PERIODICALS IN THE PERIOD FROM 2006 TO 2017
}

\author{
RAIMUNDA LETÍCIA DO NASCIMENTO ${ }^{1}$ \\ ANA SARA LEITE SANTOS ${ }^{2}$ \\ AUGUSTO CÉZAR DE AQUINO CABRAL ${ }^{3}$ \\ SANDRA MARIA DOS SANTOS ${ }^{4}$ \\ MARIA NAIULA MONTEIRO PESSOA ${ }^{5}$
}

\begin{abstract}
RESUMO: Este artigo tem como objetivo principal analisar a produção científica sobre as teorias na administração pública brasileira. Sua relevância é a de fornecer um mapeamento das publicações na área de administração pública brasileira nos últimos 12 anos, que permitirá fazer um diagnóstico da área no período, comparar com estudos anteriores e fornecer perspectivas para os pesquisadores e demais interessados na área. Trata-se de um estudo exploratório-descritivo com abordagem quantitativa, utilizando o método de pesquisa bibliométrico. Os procedimentos técnicos são documentais com consulta aos periódicos indexados na base de dados SPELL (Scientific Periodicals Eletronic Library) no período de 2006 a 2017. Observou-se que a produção acadêmica em teorias na administração pública brasileira cresceu no período; os pesquisadores estão concentrados na região sudeste; os temas mais abordados são gestão pública e gestão social; as teorias mais utilizadas são as que pertencem à corrente da nova administração pública; o setor mais estudado são as instituições de ensino; e as pesquisas são empíricas, de abordagem qualitativa, de natureza descritiva, predominando o método estudo de caso.
\end{abstract}

Palavras-chave: Administração Pública; Teorias; Estudo Bibliométrico; Brasil; Brasileira.

ABSTRACT: This article has as main objective to analyze the scientific production about the theories in the Brazilian public administration. Its relevance is to provide a mapping of the publications around Brazilian public administration in the last 12 years, which will make a diagnosis of the area in the period, compared with previous studies and provide perspectives for researchers and other interested parties in the area. This is an exploratory-descriptive study with a quantitative approach, a bibliometric research method. The technical procedures are documentary with reference to periodicals indexed in the SPELL (Scientific Periodicals Electronic Library) database from 2006 to 2017. It was observed that the academic production in theories in the Brazilian public administration grew during the period; the researchers are concentrated in the southeast region; the most discussed topics

\footnotetext{
Data de submissão: 16/06/2017 Data de aceite: 02/07/2018 Data de publicação: 07/08/2018

1 Mestranda em Administração e Controladoria pela Universidade Federal do Ceará

2 Mestranda em Administração e Controladoria pela Universidade Federal do Ceará

3 Professor Doutor da Faculdade de Economia, Administração, Atuária e Contabilidade da Universidade Federal do Ceará

4 Professora Doutora da Faculdade de Economia, Administração, Atuária e Contabilidade da Universidade Federal do Ceará

5 Professora Doutora da Faculdade de Economia, Administração, Atuária e Contabilidade da Universidade Federal do Ceará
} 
are public management and social management; the most used theories are those that belong to the stream of the new public administration; the most studied sector is educational institutions; and the researches are empirical, of qualitative approach, of descriptive nature, predominating the case study method.

Keywords: Public Administration; Theories; Bibliometric Study; Brazil; Brazilian.

\section{INTRODUÇÃO}

A produção científica possibilita a construção do conhecimento nos mais diversos âmbitos de estudo. Esse conhecimento pode ser divulgado por meio de muitas formas como teses, dissertações, monografias, livros, artigos de periódicos, resenhas, seminários, encontros, congressos, entre outras opções.

Mapear e conhecer trabalhos acadêmicos publicados em determinada área, por meio de revisões sistemáticas, é uma das formas que possibilita a avaliação e a reflexão desses trabalhos e da área em questão. As revisões são, em geral, feitas por técnicas tradicionais no meio acadêmico, como a análise bibliométrica (CARDOSO; MENDONÇA NETO; RICCIO, 2005).

O campo da administração pública no Brasil já foi caracterizado como à deriva, que enfrenta uma crise intelectual e necessita de uma nova perspectiva (MEZZOMO; LAPORTA, 1994). Entretanto, devido à sua relevância e a de seus temas, tem-se verificado o crescimento dos estudos nessa área e o interesse pelos trabalhos realizados (HOCAYEN-DASILVA; ROSSONI; FERREIRA JÚNIOR, 2008).

Fadul, Silva e Cerqueira (2011) destacam que a administração pública brasileira é um campo com fragilidades teóricas e conceituais e necessita encontrar caminhos que possam auxiliar na construção de conhecimentos científicos cumulativos capazes de favorecer o seu desenvolvimento. Pires et al. (2014) apontam a concretização e o crescimento desse campo perante a revalorização e a ampliação do setor público no país.

Vários estudos bibliométricos objetivaram analisar esse crescimento. Destacamse os trabalhos de: Pacheco (2003) e Fadul, Silva e Cerqueira (2011) sobre o campo da administração pública; Hocayen-da-Silva, Rossoni e Ferreira Júnior (2008) sobre administração pública e gestão social; Araújo Júnior e Martins (2014) sobre gestão por competências; Matos, Venâncio e Dutra (2014) sobre gestão estratégica; e Akim e Mergulhão (2015) sobre medição de desempenho. Destacam-se, ainda, trabalhos de mapeamento da produção científica em administração pública em periódicos específicos, como o de Mezzomo e Laporta (1994) e Ribeiro (2014), sobre a Revista de Administração Pública (RAP), e Keinert e Vaz (1994), sobre a Revista do Serviço Público (RSP).

O processo histórico da administração pública brasileira é marcado pela formação de correntes, paradigmas e teorias que caracterizaram momentos específicos de cada época do estruturamento deste setor. Analisar o estado da arte dessa área é relevante para o desenvolvimento das suas pesquisas. Para isso, faz-se necessário verificar a dinâmica da sua produção científica, o perfil dos pesquisadores, quais os temas que estão sendo abordados, as teorias que estão sendo pesquisadas, os campos ou setores estudados e os procedimentos metodológicos adotados.

Esse trabalho é importante por fornecer um mapeamento das publicações na área de administração pública brasileira nos últimos 12 anos, que permitirá fazer um 
diagnóstico da área no período, comparar com estudos anteriores e fornecer perspectivas para os pesquisadores e demais interessados na área. O presente artigo contribui para analisar as produções científicas atinentes à área da administração pública, possibilitando a avaliação e a reflexão em torno desses estudos. A pesquisa justifica-se pela necessidade de estudos mais detalhados sobre a administração pública brasileira com o intuito de avaliar o estado da arte desse campo, proporcionando informações que poderão nortear os trabalhos acerca das teorias na administração pública no Brasil.

Para identificar o estado da arte das publicações sobre teoria na área da administração pública brasileira, foi realizado um estudo bibliométrico utilizando a base de dados SPELL (Scientific Periodicals Eletronic Library), nos últimos 12 anos. A questão de pesquisa se define em: como se caracteriza a produção científica na área de administração pública brasileira?

Foram definidas as seguintes hipóteses: (1) a produção científica sobre teoria em administração pública cresceu nos últimos anos; (2) os pesquisadores estão concentrados na região sudeste; (3) os temas recorrentes são sobre análise organizacional; (4) as teorias utilizadas pertencem à corrente da nova administração pública; (5) o setor mais estudado envolve as universidades e (6) as pesquisas desenvolvidas têm predominância da abordagem qualitativa, de natureza descritiva e como procedimento estudo de caso.

Assim, o estudo tem como objetivo geral analisar a produção científica sobre as teorias na administração pública brasileira. Apresenta como objetivos específicos: (1) verificar a dinâmica da produção científica no período estudado; (2) identificar o perfil de autoria; (3) identificar os temas recorrentes; (4) identificar as teorias mais utilizadas; (5) identificar os campos/setores mais estudados e (6) identificar os procedimentos metodológicos adotados.

Para atingir o objetivo desta pesquisa, realizou-se um estudo exploratóriodescritivo com abordagem quantitativa, utilizando o método de pesquisa bibliométrico. Os procedimentos técnicos são documentais com consulta aos periódicos indexados na base de dados SPELL no período de 2006 a 2017.

O artigo está organizado em cinco seções. A primeira seção corresponde a esta introdução, a segunda seção aborda a fundamentação teórica, a terceira seção refere-se à metodologia do trabalho, a quarta seção consiste no levantamento e análise dos dados e, por fim, na quinta seção apresentam-se as conclusões.

\section{REFERENCIAL TEÓRICO}

Para analisar a produção científica sobre as teorias na administração pública brasileira expõe-se, a seguir, um referencial teórico contendo os seguintes tópicos: administração pública brasileira e sua trajetória, teorias na administração pública e estudos bibliométricos sobre o tema.

\subsection{A administração pública brasileira e sua trajetória}

A evolução da administração pública brasileira como campo de conhecimento foi analisada por Keinert (1994) que delimita quatro grandes períodos paradigmáticos por meio do qual ela evoluiu. Os paradigmas identificados foram: administração pública como ciência jurídica, administração pública como ciência administrativa, administração pública como ciência política e administração pública como administração pública.

Mezzomo e Laporta (1994) realizaram um estudo bibliométrico das publicações da Revista de Administração Pública (RAP) desde a sua fundação em 1967 até 1992, 
relacionando o conteúdo da revista a esses paradigmas que expressam as principais correntes de pensamento que constituíram o campo da administração pública. A RAP é um importante e influente periódico que tem contribuído historicamente para o aperfeiçoamento das pesquisas neste setor.

Em complemento, Keinert e Vaz (1994) fizeram uma reconstituição histórica da trajetória da Revista do Serviço Público (RSP) de 1937 a 1989, destacando as características por ela assumidas em cada período e o papel cumprido na evolução do campo de conhecimento em administração pública. A RSP é um periódico de grande longevidade e importância na formulação dos primórdios do pensamento administrativo brasileiro. Segundo os autores (1994), ela possui duas tendências básicas conflitantes: a de ser uma revista oficial para divulgar a filosofia do governo em exercício e a de ser uma revista científica, publicando artigos de caráter acadêmico, plural e crítico.

O paradigma da administração pública como ciência jurídica predomina no princípio do estudo de administração pública no Brasil (1900-1929) (KEINERT, 1994). De acordo com Keinert e Vaz (1994), as contribuições da perspectiva jurídica são expressivas nos primeiros períodos uma vez que a sua atuação era maior. O problema dessa área era limitado à elaboração de leis e regulamentos de aplicação, sendo dependente do direito administrativo. Explica-se, assim, a grande influência exercida no Brasil por esse paradigma, que apesar de não ser mais o dominante, continua bastante forte (KEINERT, 1994).

O paradigma da administração pública como ciência administrativa (1930-1979) é marcado pela grande influência dos chamados "princípios da administração" que traziam em si a ideia de neutralidade e aplicabilidade a qualquer contexto, permitindo que se equiparasse a administração pública à administração de empresas. Dada a vigência deste paradigma por um longo período de tempo, ele é dividido em três fases distintas: (1) o estado administrativo (1930-1945), que se inicia com a Revolução de 30 e é marcado pela ideia de racionalização, baseada nos teóricos da Escola Clássica; (2) a administração para o desenvolvimento (1946-1964), marcado pela ideologia desenvolvimentista, reforçando ainda mais a ideia de que dificilmente se poderá planejar o desenvolvimento enquanto o país não estabelecer uma administração pública; e (3) o intervencionismo estatal (1965-1979), período em que o Estado começa a gerir grandes organizações, ocorrendo um crescimento da máquina governamental com vistas a aumentar sua capacidade de intervenção, centralização e controle (KEINERT, 1994). Mezzomo e Laporta (1994) constatam o foco nas ciências administrativas na maioria das publicações da RAP de 1967 a 1979. Por outro lado, Keinert e Vaz (1994) observam sua hegemonia em todos os períodos.

O paradigma da administração pública como ciência política (1980-1989) se desenvolve no período em que o país vivencia intensa mobilização político-social e um processo de reorganização institucional. O novo paradigma aponta para uma nova configuração do campo e os estudos começam a utilizar um instrumental teórico proveniente das ciências políticas. O domínio do tecnicismo característico do paradigma anterior dá lugar agora a um politicismo que reedita a velha e criticada proposição taylorista da separação entre os que concebem e os que executam (KEINERT, 1994). As publicações da RAP com enfoque dessas ciências crescem e superam os trabalhos da ciência administrativa nesse período (MEZZOMO; LAPORTA, 1994). Na RSP, a visão da ciência política experimenta crescimento constante em todo o período de existência da revista, ampliando o instrumental teórico das análises organizacionais (KEINERT; VAZ, 1994).

A partir da mobilização social do período anterior, o conceito de cidadania e a noção de direitos são consolidados, ocorrendo o fortalecimento da cultura democrática. 
Surge o paradigma administração pública como administração pública (1989-1992) que se baseia na formulação, execução e avaliação de planos governamentais e no manejo de interesses das organizações políticas e sociais que se encontram em conflito. Inicia-se o debate de questões como o controle social a partir da participação da sociedade civil na gestão pública, a redução do tamanho do Estado por meio de privatizações e descentralização e formas alternativas de gestão como as parcerias público-privado. O novo papel do Estado parece ser o de catalisador de energias e potencialidades governamentais e comunitárias (KEINERT, 1994). Para Mezzomo e Laporta (1994), os paradigmas que se delineavam nos períodos anteriores parecem consolidar-se e equilibrar-se.

Os estudos mais recentes sobre a evolução do campo da administração pública brasileira realizam a análise histórica do ensino de graduação nessa área. Coelho e Nicolini (2010) observam três ciclos dessa formação acadêmica entre os anos de 1952 e 1994 . O primeiro mostra a irradiação do ensino de graduação em administração pública entre 1952 e 1965. O segundo enfoca o auge e o declínio deste ensino no período compreendido entre 1966 e 1982. Por fim, no terceiro tem-se novas proposições de formação que emergem nos anos de 1983 a 1994.

Para Vendramini (2013), a pressão por resultados, a exigência por transparência, a necessidade de articulação com diferentes instituições e o controle social demandam uma formação acadêmica dos gestores públicos. A autora salienta que a gestão das organizações que prestam serviços à sociedade está sendo colocada em xeque diante da revalorização dessa carreira ocorrida nos últimos anos no Brasil, da busca pelo reconhecimento das idiossincrasias desse campo do saber pela comunidade científica e da crescente participação social na gestão das políticas.

\subsection{Teorias na administração pública}

Andion (2012) identifica e aprofunda a análise dos paradigmas presentes no campo teórico da administração pública no Brasil, partindo dos trabalhos de Keinert (1994). A pesquisadora agrupou as teorias utilizadas em quatro correntes teóricas principais: estadocêntrica, pluralista, nova administração pública e novo serviço público e correlacionou com os paradigmas propostos por Morgan (2007): humanismo radical, estruturalismo radical, interpretativo e funcionalista.

A corrente estadocêntrica é a mais influente no campo da administração pública no Brasil, predominando desde os primórdios até o final dos anos 1970. Abrange os enfoques das ciências jurídicas e das ciências administrativas e tem como foco principal a ampliação da competência e da racionalidade funcional. Segue o paradigma funcionalista que enfatiza a concepção de leis universais que permitam explicar o funcionamento da administração pública e o comportamento dos atores políticos, com vistas a promover ordem e equilíbrio. Engloba a teoria da administração científica, a teoria da burocracia, a progressive public administration, as teorias comportamentais e as teorias de sistemas (ANDION, 2012).

A corrente pluralista predomina nos anos 1980 e tem a administração pública como campo político. O principal mérito desses estudos foi trazer à tona a importância da sociedade civil enquanto ator político, dando ênfase a uma visão crítica no âmbito da administração pública brasileira que se torna mais permeável à participação popular. Segue o paradigma do humanismo radical quando enfatiza a mobilização da sociedade civil e a sua atuação enquanto sujeito de mudança social. Abrange as teorias sobre os novos movimentos sociais, as teorias da democracia participativa e as teorias críticas na administração pública. 
A corrente pluralista segue também o paradigma do estruturalismo radical quando enfatiza as relações entre Estado e sociedade, ou seja, o Estado como espaço de luta entre as classes sociais. As teorias associadas a esse paradigma são as teorias dos movimentos sociais e as teorias sobre o estado capitalista (ANDION, 2012).

A corrente da nova administração pública emerge nos anos 1990 e tem a visão de administração pública como ciência do gerenciamento. É composta por uma série de valores e princípios administrativos que configuram diferentes modelos de gestão e são voltados para a eficiência, a descentralização e a excelência do serviço público. Segue o paradigma funcionalista com a teoria das escolhas públicas, a teoria da agência, o institucionalismo e o neo-institucionalismo das escolhas racionais, o institucionalismo da economia política, o gerencialismo e neo-gerencialismo, governança corporativa, o neoinstitucionalismo econômico, a teoria dos custos de transação e a teoria da boa governança (ANDION, 2012).

A corrente do novo serviço público é muito recente e suas ideias se disseminam no Brasil após a consolidação democrática a partir da segunda metade dos anos 1990. Ela surge como um contraponto às correntes estadocêntrica e da nova administração pública. Tem por base as teorias democráticas e da cidadania, os modelos de comunidade e da sociedade civil, o humanismo organizacional e a teoria do discurso. Segue o paradigma interpretativo que foca na compreensão da realidade da administração pública, considerando a subjetividade da política e importância dos valores. Compreende as teorias da coprodução dos serviços públicos; as teorias da participação comunitária e da sociedade civil; as teorias críticas, humanistas e do discurso e as novas teorias do desenvolvimento territorial e sustentável (ANDION, 2012).

A partir da análise das correntes teóricas e dos paradigmas, Andion (2012) observa o predomínio do paradigma funcionalista cujas concepções embasam os pressupostos das correntes dominantes no campo da administração pública brasileira: a corrente estadocêntrica e a nova administração pública. Esse predomínio do paradigma funcionalista tem estimulado uma visão objetivista no campo, com pouco espaço para a historicidade, o conflito e a subjetividade dos atores políticos. Entretanto, a corrente pluralista e a corrente do novo serviço público que emergiram nas últimas décadas, vêm lançar novas bases de compreensão da administração pública e reconfigurar a sua identidade enquanto campo científico, a partir do diálogo com outras disciplinas das ciências sociais. Isso trará novos pressupostos epistemológicos, teóricos e metodológicos para o campo, promovendo o seu enriquecimento.

Souza (1998) aprofunda a discussão sobre os rumos das pesquisas em administração pública no Brasil. A autora analisa o estado da arte dessa área e propõe uma agenda de temas, teorias e caminhos metodológicos que podem ser utilizados pelos pesquisadores da disciplina. Ela argumenta que a disciplina não constitui um único tipo de pensamento ou de teoria, mas sim é o resultado da superposição de várias outras disciplinas, sem que isso signifique descuido metodológico ou "salada" teórica. Neste trabalho retomamos o estudo das diversas teorias utilizadas no campo da administração pública.

As pesquisas da administração pública apresentam dificuldades com relação à teoria. As principais questões que se discutem são: o papel da teoria na pesquisa, dificuldade de relacionar a teoria com o problema estudado e a especificidade da teoria nessa área. $\mathrm{A}$ pesquisadora apresenta algumas abordagens da ciência política, mas que podem ser utilizadas em várias áreas da administração pública, em especial nos estudos sobre políticas 
públicas e instituições políticas. Essas abordagens são: teoria normativa, abordagem institucional, teoria do discurso, teoria da escolha racional e análise behaviorista (SOUZA, 1998).

A abordagem normativa se refere à aplicação de regras morais. A abordagem institucional se reporta ao estudo das instituições, lida com as regras, procedimentos e a organização formal das instituições e seu impacto na prática político-administrativa. A análise institucional se desdobra em três subcampos: estudos constitucionais, administração pública a partir da teoria das organizações e novo institucionalismo. A abordagem behaviorista concentra-se na explicação do comportamento político nos níveis individual e agregado e enfatiza a necessidade do uso de teorias baseadas em fatos. A abordagem da teoria da escolha racional surge a partir dos anos 1950 e a hipótese central é a de que o comportamento político pode ser entendido como o resultado de escolhas movidas pelo auto interesse do indivíduo, desdobrando-se em várias subáreas, tais como teoria dos jogos e teoria da escolha pública (SOUZA, 1998).

Com base no exposto, percebe-se a multiplicidade de teorias aplicadas aos estudos em administração pública e a superposição de várias disciplinas, tornando o campo multifacetado. Sendo assim, verifica-se uma preocupação dos estudiosos com os temas, teorias e metodologias utilizadas e a evolução desse campo do conhecimento como ciência.

\subsection{Estudos bibliométricos}

Vários estudos utilizaram a bibliometria para investigar o campo da administração pública, visando conhecer a sua evolução, as pesquisas que são desenvolvidas e os seus rumos. Pacheco (2003) discute a administração pública como campo de pesquisa e estuda a sua evolução de 1995 a 2002, a partir dos trabalhos apresentados nos Encontros da ANPAD (EnANPAD) e os artigos publicados em duas revistas brasileiras especializadas: a RAP e a RSP. O autor confirma o caráter propositivo da produção em administração pública e aponta outros fatores que merecem debate e reflexão para fazer avançar a pesquisa na área, dentre eles: a tendência de pesquisadores a se autorreferirem, a diluição temática e a adoção acrítica de teorias desenvolvidas em outras disciplinas.

Hocayen-da-Silva, Rossoni e Ferreira Júnior (2008) apresentam um quadro geral da produção científica na área de administração pública e gestão social, com base em dados levantados a partir dos artigos publicados nos anais do EnANPAD no período de 2000 a 2005. Os autores verificaram que (1) houve um crescimento constante no número de artigos publicados na área de administração pública e gestão social de 2000 a 2004; porém, no ano de 2005 foi identificada uma queda no número de publicações; (2) a subárea com maior número de trabalhos foi a de gestão pública e governança, com 185 artigos publicados; (3) a média do número de autores por artigo foi de 1,94, sugerindo que as publicações são resultados de interações baseadas em relacionamentos ou interesses de pesquisa pessoais; (4) a grande maioria dos artigos foi classificada como do tipo teórico-empírico; (5) nos artigos teórico-empíricos o método de pesquisa predominante foi o qualitativo; (6) nos trabalhos qualitativos as estratégias de pesquisa mais utilizadas foram o estudo de caso e a pesquisa documental; (6) nos trabalhos quantitativos a survey foi a mais utilizada e (7) as instituições mais prolíferas se encontram concentradas na região sudeste do país.

Fadul, Silva e Cerqueira (2011) fazem o estudo da produção sobre administração pública a partir dos Encontros de Administração Pública e Governança (EnAPGs) com o objetivo de identificar do que os trabalhos tratam, como os temas são apresentados, o que eles traduzem e indicam a respeito da área e se essa produção tem sido capaz de construir 
conhecimentos científicos cumulativos que possam auxiliar o desenvolvimento desse campo. Os pesquisadores concluíram que: (1) o desenvolvimento da produção científica da área é influenciado pelas agendas de governo; (2) há uma preferência dos autores por temas que estão em moda; (3) em geral os trabalhos apresentam apenas resultados empíricos com pouca ou nenhuma geração de novos conhecimentos específicos para o campo; (4) as discussões de caráter teórico e metodológico mais aprofundado são escassas; (5) grande parte dos autores tem concentrado suas pesquisas em conceitos que não são exclusivos da administração pública, mas com discussões elaboradas a partir de teorias desenvolvidas em outros campos; (6) essa produção não está retratando o campo na sua profundidade; e (7) a grande concentração dos trabalhos publicados está nos temas que tratam de políticas públicas e dos aspectos gerenciais das organizações governamentais.

O Quadro 1 apresenta o objetivo geral, a metodologia e os resultados desses trabalhos bibliométricos:

Quadro 1: Síntese dos trabalhos bibliométricos

\begin{tabular}{|c|c|c|c|}
\hline Autores (ano) & Objetivo geral & Metodologia & Resultados \\
\hline $\begin{array}{l}\text { Pacheco } \\
(2003)\end{array}$ & $\begin{array}{l}\text { Analisar a recente } \\
\text { produção } \\
\text { brasileira na área } \\
\text { de pesquisa em } \\
\text { administração } \\
\text { pública. }\end{array}$ & $\begin{array}{l}\text { Utiliza como base os } \\
\text { artigos publicados } \\
\text { entre } 1995 \text { e } 2002 \text { nas } \\
\text { revistas especializadas } \\
\text { RAP e RSP, além dos } \\
\text { trabalhos apresentados } \\
\text { durante os EnANPAD. O } \\
\text { autor não especifica os } \\
\text { procedimentos } \\
\text { metodológicos. }\end{array}$ & $\begin{array}{l}\text { Confirma o caráter propositivo da produção } \\
\text { em administração pública. Aponta outros } \\
\text { fatores que merecem debate e reflexão: a } \\
\text { tendência de pesquisadores a se auto- } \\
\text { referirem, a diluição temática e a adoção } \\
\text { acrítica de teorias desenvolvidas em outras } \\
\text { disciplinas. }\end{array}$ \\
\hline $\begin{array}{l}\text { Hocayen-da- } \\
\text { Silva, Rossoni e } \\
\text { Ferreira Júnior } \\
\text { (2008) }\end{array}$ & $\begin{array}{l}\text { Apresentar um } \\
\text { quadro geral da } \\
\text { produção } \\
\text { científica em } \\
\text { administração } \\
\text { pública e gestão } \\
\text { social. }\end{array}$ & $\begin{array}{l}\text { Base de dados } \\
\text { constituída de artigos } \\
\text { publicados nos anais do } \\
\text { EnANPAD, no período } \\
\text { de } 2000 \text { a } 2005 . \\
\text { Pesquisa descritiva, } \\
\text { quantitativa e } \\
\text { documental. }\end{array}$ & $\begin{array}{l}\text { Verificou-se que houve um crescimento } \\
\text { constante no número de artigos publicados } \\
\text { na área de administração pública e gestão } \\
\text { social de } 2000 \text { a 2004; a subárea com maior } \\
\text { número de trabalhos foi a de gestão pública } \\
\text { e governança; as publicações são resultados } \\
\text { de interações baseadas em relacionamentos } \\
\text { ou interesses de pesquisa pessoais; a grande } \\
\text { maioria dos artigos foi classificada como do } \\
\text { tipo teórico-empírico; o método de pesquisa } \\
\text { predominante foi o qualitativo; as estratégias } \\
\text { de pesquisa mais utilizadas foram: estudo de } \\
\text { caso, pesquisa documental e survey; e as } \\
\text { instituições mais prolíficas se encontram } \\
\text { concentradas na região sudeste do país. }\end{array}$ \\
\hline $\begin{array}{l}\text { Fadul, Silva e } \\
\text { Cerqueira } \\
\text { (2011) }\end{array}$ & $\begin{array}{l}\text { Realizar uma } \\
\text { análise do campo } \\
\text { da Administração } \\
\text { Pública utilizando } \\
\text { a produção } \\
\text { científica } \\
\text { publicada nos } \\
\text { anais dos EnAPGs, } \\
\text { explicitando o que } \\
\text { ela traduz e indica } \\
\text { a respeito do } \\
\text { campo. }\end{array}$ & $\begin{array}{l}\text { Base de dados } \\
\text { constituída de todos os } \\
\text { artigos publicados nos } \\
\text { anais dos quatro } \\
\text { Encontros de } \\
\text { Administração Pública e } \\
\text { Governança (EnAPGs), } \\
\text { realizados nos anos de } \\
\text { 2004, 2006, 2008 e } \\
\text { 2010. Pesquisa } \\
\text { descritiva. }\end{array}$ & $\begin{array}{l}\text { Os resultados mostram uma variedade de } \\
\text { assuntos abordados, mas indicam que essa } \\
\text { produção não parece se desenvolver de } \\
\text { modo contínuo e sistemático sobre } \\
\text { determinados conceitos, recortes teóricos ou } \\
\text { objetos de pesquisa. Indicam a ausência de } \\
\text { discussão e aprofundamento teóricos mais } \\
\text { efetivos, lançando uma preocupação sobre o } \\
\text { futuro do campo, pois as discussões } \\
\text { realizadas nos trabalhos analisados parecem } \\
\text { não contribuir para o seu fortalecimento, ao } \\
\text { contrário, tornam-no frágil, indefinido e }\end{array}$ \\
\hline
\end{tabular}


Fonte: Elaborado pelos autores (2017).

Esses trabalhos contribuíram para um diagnóstico do campo e revelam preocupação com as pesquisas em administração pública brasileira, colocando em discussão as especificidades da área e o quanto ela carece de mais estudos e pesquisas de qualidade para a sua consolidação.

\section{METODOLOGIA}

Para que a questão de pesquisa fosse respondida de forma satisfatória, foi estabelecido previamente o procedimento metodológico a ser seguido neste estudo. Assim, este trabalho caracteriza-se pela reflexão sobre a produção científica brasileira sobre as teorias na administração pública e foi conduzido pelo método de pesquisa bibliométrico.

Para Otlet (1986), a medida é uma forma superior de enfoque em todos os campos do conhecimento e a bibliometria possibilita a formação de um conjunto coordenado de medidas que farão referência à objetos, fenômenos ou fatos de um documento. Macias-Chapula (1998) acrescenta que a bibliometria estuda os fatores quantitativos de uma pesquisa incluindo sua elaboração e propagação de informações registradas. Guedes e Borschiver (2005) definem a pesquisa bibliométrica como uma ferramenta que possibilita o exame e a inferência de indicadores de tratamento do conhecimento, necessários para a avaliação da ciência por uma comunidade científica.

Quanto ao objetivo desta investigação, a pesquisa classificou-se como exploratória-descritiva. Acevedo e Nohara (2006, p. 46) retratam que o principal objetivo da pesquisa exploratória "é proporcionar maior compreensão do fenômeno que está sendo investigado, permitindo assim, que o pesquisador delineie de forma mais precisa o problema". Locke et al. (2010) comentam que a pesquisa descritiva visa conhecer o cenário de uma situação, expressando o resultado do fenômeno em números.

Em relação à abordagem do problema, esta pesquisa classifica-se como quantitativa. A pesquisa quantitativa oferece a possibilidade de generalização dos resultados de forma mais ampla, com enfoque sobre pontos específicos e um panorama de contagem e magnitude em relação aos fenômenos (SAMPIERI; COLLADO; LUCIO, 2013). Quanto aos procedimentos, utilizou-se de pesquisa documental dos periódicos publicados de 2006 a 2017, obtidos mediante consulta ao banco de dados SPELL (Scientific Periodicals Eletronic Library). Essa base de dados foi escolhida por agregar a produção científica nacional disponível na internet nas áreas de Administração Pública e de Empresas, Contabilidade e Turismo. Estabeleceu-se como período os últimos 12 anos, uma vez que já haviam sido realizados estudos sobre a produção científica da administração pública brasileira com períodos anteriores, porém analisando outras bases de dados.

A pesquisa foi dividida em três etapas: a primeira consistiu no levantamento bibliográfico, a segunda envolveu a pesquisa de periódicos relacionados ao tema na base de dados SPELL e a terceira constituiu-se na catalogação da produção científica encontrada. $\mathrm{Na}$ primeira etapa, realizou-se um estudo bibliográfico sobre o tema administração pública e suas teorias nos artigos publicados em periódicos online e livros, definindo-se as hipóteses do estudo pelos resultados encontrados dos trabalhos anteriores. Na segunda etapa, realizou-se uma pesquisa bibliométrica com a coleta de artigos publicados no banco de dados do portal de periódicos SPELL. Os artigos foram selecionados com a utilização dos termos de procura no campo resumo. Os termos de procura foram formados pela palavra 
"teoria" associada aos termos "administração pública", "gestão pública" e "serviço público", bem como os respectivos termos em inglês e espanhol. Efetuando a pesquisa pelos termos mencionados foi obtida a população de 123 artigos. Procedeu-se a leitura desses artigos para selecionar os que se enquadrassem na temática. Para tanto, o critério utilizado foi que a teoria contida no artigo estivesse relacionada com a construção e evolução da administração pública. Assim, a amostra foi composta por 58 trabalhos. Na terceira e última etapa, referente à catalogação das informações, procedeu-se a leitura dos artigos e o preenchimento do instrumento de coleta.

$O$ instrumento de coleta utilizado foi uma planilha elaborada no programa Microsoft Excel versão 16.0, com roteiro estruturado com os seguintes itens: identificação da revista, título do artigo, perfil do(s) autor(es) (nome, formação, instituição), ano de publicação, tema central, teoria abordada, campo/setor de estudo e procedimentos metodológicos (classificação quanto ao tipo de pesquisa, quanto aos procedimentos, quanto à abordagem, quanto aos objetivos, método de coleta de dados e método de análise de dados). Posteriormente, na análise dos resultados, esses dados foram organizados em tabelas.

O método de análise de dados utilizado foi a análise de conteúdo, que consiste em aproveitar partes isoladas de um texto, conforme o problema observado, possibilitando a sua comparação com outros textos selecionados da mesma maneira. Esse tipo de análise se dá através de categorias com a finalidade de constituir elementos proeminentes da teoria (KEINERT, 2007). Segundo Chizzotti (2006), a análise de conteúdo consiste em interpretar o conteúdo de um texto desenvolvido, que adotou normas sistemáticas de extrair os significados temáticos por meio de seus elementos. De forma complementar, foi criada uma nuvem de palavras com o auxílio do programa MAXQDA $18^{\circledR}$ (2018) para indicar a predominância dos temas recorrentes.

Os dados foram organizados em tabelas, conforme os objetivos específicos. Para atender o primeiro objetivo específico, que é o de verificar a dinâmica da produção científica no período estudado, foi tabelada a quantidade de publicações de acordo com a identificação da revista e ano de publicação. Para o segundo objetivo específico, que visa identificar o perfil de autoria, foram quantificados o número de autores por artigo e os autores mais produtivos, identificando-se também a formação dos autores e as instituições a que eles pertencem. Para o terceiro objetivo específico, identificar os temas recorrentes, os temas identificados foram agrupados em categorias de acordo com as especificidades de cada assunto e foi criada uma nuvem de palavras para constatar as mais utilizadas. Para o quarto objetivo, identificar as teorias mais utilizadas, foi seguida a divisão proposta por Andion (2012), sendo primeiramente quantificados os artigos que abordaram as correntes de forma ampla, e, posteriormente, foram agrupadas as teorias pesquisadas nos demais artigos de acordo com a corrente a qual pertence; entretanto, algumas teorias não se enquadraram na classificação de Andion (2012), não sendo citadas neste trabalho. Para o quinto objetivo, identificar os campos/setores mais estudados, os setores abordados foram agrupados em categorias de acordo com as suas características. Por fim, para o sexto objetivo, identificar os procedimentos metodológicos adotados, tabulou-se os dados de acordo com a classificação quanto ao tipo de pesquisa, quanto aos procedimentos, quanto à abordagem, quanto aos objetivos, método de coleta de dados e método de análise de dados.

Os resultados encontrados são expostos e discutidos na seção a seguir também de acordo com os objetivos específicos. 


\section{RESULTADOS}

\subsection{Dinâmica da produção científica}

A Tabela 1 apresenta a dinâmica da produção científica acerca das teorias na administração pública no período de 2006 a 2017. Os periódicos que mais publicaram foram os Cadernos EBAPE.BR e a Revista de Administração Pública, com 7 publicações cada. Observa-se um crescimento na quantidade de publicações a partir de 2011 , sendo que os anos 2014 e 2015 apresentaram maior produtividade. Constata-se que em 2016 ocorreu um declínio e em 2017 houve uma retomada. É importante destacar que no período de 2011 a 2017 foram publicados 46 artigos (79\%), o que sugere que a produção acadêmica em teorias na administração pública esteve em expansão nos últimos anos.

Tabela 1: Dinâmica da produção científica

\begin{tabular}{|c|c|c|c|c|c|c|c|c|c|c|c|c|}
\hline lentificação da revista & ర్ర & 옹 & 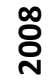 & 유 & 웅 & 곰 & ్ㅗㅇ & $\stackrel{m}{\stackrel{n}{\sim}}$ & 吕 & 瓷 & $\begin{array}{l}0 \\
\stackrel{-}{0}\end{array}$ & 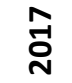 \\
\hline
\end{tabular}

Cadernos EBAPE.BR

Revista de Administração

Pública

Administração Pública e Gestão

Social

Revista de Administração

Contemporânea

Amazônia, Organizações e

Sustentabilidade

Brazilian Administration Review

Organizações \& Sociedade

Revista Capital Científico -

Eletrônica

Revista do Serviço Público

Periódicos com apenas 1

publicação

$$
\text { Total }
$$

1

3

1

11

1

1

$\begin{array}{lllll}1 & 1 & 1 & 1 & 4 \\ & 2 & & 1 & 4\end{array}$

11

2

1

1

2

2

2

2

1

$\begin{array}{llllllllllll}2 & 2 & 1 & 1 & 2 & 2 & 3 & 2 & 6 & 2 & 3 & 26\end{array}$

$\begin{array}{lllllllllllll}3 & 3 & 2 & 1 & 3 & 5 & 7 & 5 & 10 & 12 & 2 & 5 & 58\end{array}$

Fonte: Elaborada pelos autores (2018).

\subsection{Perfil de autoria}

Para a definição do perfil de autoria, levou-se em consideração o nome de todos os autores dos artigos da amostra pesquisada. Observa-se que os estudos foram realizados por no máximo quatro pesquisadores, sendo que o número predominante foi de dois autores por artigo, equivalendo a $36 \%$ dos trabalhos (conforme Tabela 2). Resultado semelhante foi encontrado por Hocayen-da-Silva, Rossoni e Ferreira Júnior (2008). Esses autores relatam que as publicações dessa área são resultantes de interações baseadas em relacionamentos ou interesses de pesquisa pessoais.

Tabela 2: Quantidade de autores por artigo

\begin{tabular}{lccc} 
& Quantidade de autores & Quantidade de artigos & $\%$ \\
\hline 1 autor & 15 & $26 \%$ &
\end{tabular}


2 autores

Fonte: Elaborada pelos autores (2018).

Com relação à produção dos autores, verifica-se que dos 125 autores/coautores, apenas 8 produziram e publicaram mais de um trabalho científico sobre teorias em administração pública (conforme Tabela 3). Sendo que o pesquisador mais produtivo publicou 3 artigos. Esse dado sugere que as pesquisas são isoladas. O campo da administração pública possui muitos pesquisadores, mas o baixo número de publicações por autor pode indicar que eles não estão comprometidos em pesquisar as teorias no campo, sendo esta uma lacuna a ser suprida para o bom desenvolvimento dessa área.

Tabela 3: Autores mais produtivos

\begin{tabular}{cllc}
\hline \multirow{2}{*}{ Ordem } & \multicolumn{1}{c}{ Autor } & \multicolumn{1}{c}{ Instituição } & $\begin{array}{c}\text { No de } \\
\text { artigos }\end{array}$ \\
\cline { 2 - 4 } & José Roberto Pereira & Universidade Federal de Lavras (UFLA) & 3 \\
2 & Ana Alice Vilas Boas & Universidade Federal de Lavras (UFLA) & 2 \\
3 & Carlos Eduardo Justen & Universidade Federal de Santa Catarina (UFSC) & 2 \\
4 & Jackeline Amantino de Andrade & Universidade Federal de Pernambuco (UFPE) & 2 \\
5 & Janann Joslin Medeiros & Universidade de Brasília (UnB) & 2 \\
6 & Maria Elisabete Pereira dos Santos & Universidade Federal da Bahia (UFBA) & 2 \\
7 & Renato Fabiano Cintra & Universidade Nove de Julho (UNINOVE) & 2 \\
8 & Saulo Fabiano Amâncio-Vieira & Universidade Estadual de Londrina (UEL) & 2 \\
\hline
\end{tabular}

Fonte: Elaborada pelos autores (2018).

$\mathrm{Na}$ Tabela 4, apresenta-se a formação dos autores. Constata-se a amplitude do grau de formação, que varia de graduandos a pós-doutor. Verifica-se a predominância de pesquisadores com o grau de doutor (37\%). Esse dado revela a maturidade teórica que eles possuem e a grande complexidade do campo que, no entanto, instiga pesquisadores em diferentes fases de formação.

Tabela 4: Formação dos autores

\begin{tabular}{|c|c|c|}
\hline Formação & Quantidade de autores & $\%$ \\
\hline Doutorado & 47 & $37 \%$ \\
\hline Doutorando & 18 & $14 \%$ \\
\hline Mestrado & 13 & $10 \%$ \\
\hline Mestrando & 6 & $5 \%$ \\
\hline Pós-doutorado & 3 & $2 \%$ \\
\hline Especialista & 1 & $1 \%$ \\
\hline Graduado & 1 & $1 \%$ \\
\hline Graduando & 1 & $1 \%$ \\
\hline Não especificado no artigo & 38 & $29 \%$ \\
\hline
\end{tabular}

Fonte: Elaborada pelos autores (2018).

Na Tabela 5, são listadas as instituições as quais os autores estão vinculados. 0 critério utilizado para a triagem dos dados informados no artigo e identificação da instituição 
segue a ordem dos seguintes quesitos: (1) a instituição que o pesquisador trabalha ou estuda; (2) a instituição onde foi formado ou (3) não especificado. Constata-se que as instituições que possuem mais autores dessa área são a Universidade Federal de Viçosa UFV e a Universidade Federal de Lavras - UFLA, que possuem 12 e 11 autores, respectivamente. Essas universidades são da região sudeste corroborando o resultado encontrado por Hocayen-da-Silva, Rossoni e Ferreira Júnior (2008) que afirmam que as instituições mais prolíferas na área de administração pública e gestão social se encontram concentradas na região sudeste do país.

Tabela 5: Instituições dos autores

\begin{tabular}{|c|c|}
\hline Formação & Quantidade de autores \\
\hline Universidade Federal de Viçosa (UFV) & 12 \\
\hline Universidade Federal de Lavras (UFLA) & 11 \\
\hline Fundação Getúlio Vargas (FGV) & 8 \\
\hline Universidade Federal de Santa Catarina (UFSC) & 6 \\
\hline Universidade de Brasília (UnB) & 5 \\
\hline Universidade do Estado de Santa Catarina (UDESC) & 5 \\
\hline Universidade Federal da Bahia (UFBA) & 5 \\
\hline Pontifícia Universidade Católica do Paraná (PUCPR) & 4 \\
\hline Universidade Federal de Minas Gerais (UFMG) & 4 \\
\hline Universidade Federal de Pernambuco (UFPE) & 4 \\
\hline Universidade Federal do Rio de Janeiro (UFRJ) & 4 \\
\hline Universidade Federal do Rio Grande do Norte (UFRN) & 4 \\
\hline Universidade Regional do Noroeste do Estado do Rio Grande do Sul (Unijuí) & 4 \\
\hline Fundação João Pinheiro (FJP) & 3 \\
\hline Universidade de São Paulo (USP) & 3 \\
\hline Universidade Estadual de Londrina (UEL) & 3 \\
\hline Centro Universitário FEI & 2 \\
\hline Fundação Dom Cabral (FDC) & 2 \\
\hline Instituto Federal de Minhas Gerais (IFMG) & 2 \\
\hline Pontifícia Universidade Católica do Rio Grande do Sul (PUCRS) & 2 \\
\hline Universidade Católica de Brasília (UCB) & 2 \\
\hline Universidade Federal da Grande Dourados (UFGD) & 2 \\
\hline Universidade Federal de Goiás (UFG) & 2 \\
\hline Universidade Federal de Sergipe (UFS) & 2 \\
\hline Universidade Federal do Paraná (UFPR) & 2 \\
\hline Universidade Nove de Julho (UNINOVE) & 2 \\
\hline Não especificado no artigo & 2 \\
\hline Instituições com 01 autor & 21 \\
\hline
\end{tabular}

Fonte: Elaborada pelos autores (2018).

\subsection{Temas recorrentes}

Na Tabela 6, são classificados os temas abordados pelos artigos analisados. Os temas gestão pública e gestão social se destacam com $16 \%$ e $12 \%$, respectivamente cada. Outros temas recorrentes são: inovação (7\%), análise organizacional (7\%), epistemologia (7\%), políticas públicas (5\%), administração pública brasileira (5\%) e compras públicas (5\%). 
Esses temas juntos, correspondem a $64 \%$ da produção analisada. Os temas elencados se deram com base na junção de assuntos em comum abordados em cada artigo.

Tabela 6: Temas abordados

\begin{tabular}{|c|c|c|c|}
\hline Ordem & Tema central & Quantidade de artigos & $\%$ \\
\hline 1 & Gestão pública & 9 & $16 \%$ \\
\hline 2 & Gestão social & 7 & $12 \%$ \\
\hline 3 & Inovação & 4 & $7 \%$ \\
\hline 4 & Análise organizacional & 4 & $7 \%$ \\
\hline 5 & Epistemologia & 4 & $7 \%$ \\
\hline 6 & Políticas públicas & 3 & $5 \%$ \\
\hline 7 & Administração pública brasileira & 3 & $5 \%$ \\
\hline 8 & Compras públicas & 3 & $5 \%$ \\
\hline 9 & Ética & 2 & $4 \%$ \\
\hline 10 & Gestão de pessoas no setor público & 2 & $4 \%$ \\
\hline 11 & Orçamento & 2 & $4 \%$ \\
\hline 12 & Processo de institucionalização & 2 & $4 \%$ \\
\hline 13 & Transparência & 2 & $4 \%$ \\
\hline 14 & Crise do Estado & 1 & $2 \%$ \\
\hline 15 & Educação fiscal & 1 & $2 \%$ \\
\hline 16 & Empresas estatais & 1 & $2 \%$ \\
\hline 17 & Governança de tecnologia de informação & 1 & $2 \%$ \\
\hline 18 & Liderança & 1 & $2 \%$ \\
\hline 19 & Modernização administrativa & 1 & $2 \%$ \\
\hline 20 & Relações internacionais & 1 & $2 \%$ \\
\hline 21 & Sistemas de incentivo em governos & 1 & $2 \%$ \\
\hline 22 & Sistemas de Informação em saúde & 1 & $2 \%$ \\
\hline 23 & Turismo & 1 & $2 \%$ \\
\hline
\end{tabular}

Fonte: Elaborada pelos autores (2018).

A Figura 1 mostra a nuvem de palavras mais frequentes gerada com base em todos os artigos da amostra. As palavras mais representativas foram "administração", "gestão", "pública" e "social" confirmando a classificação dos temas "gestão pública" e "gestão social" como o mais recorrente.

Figura 1: Nuvem de palavras mais frequentes nos artigos da amostra 


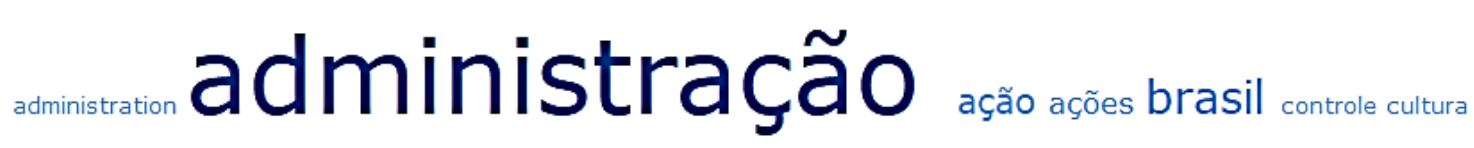

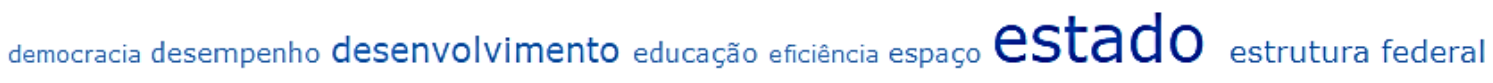
gestão processo processo onitas public pública ${ }_{\text {puiblicas }}$ sociedade teoria theory universidade

Fonte: Elaborada pelos autores, gerado pelo Programa MAXQDA $18^{\circledR}$ (2018).

Hocayen-da-Silva, Rossoni e Ferreira Júnior (2008) analisando os artigos publicados nos anais do EnANPAD encontraram maior número de trabalhos na subárea de gestão pública e governança. Por outro lado, Fadul, Silva e Cerqueira (2011), analisando as publicações dos EnAPGs, constataram que a grande concentração está nos temas que tratam de políticas públicas e dos aspectos gerenciais das organizações governamentais. Os resultados encontrados no presente trabalho apontam que a gestão pública vem sendo abordada de forma abrangente, sendo o tema mais pesquisado.

\subsection{Teorias utilizadas e respectivas correntes}

A análise da teoria utilizada pelos autores possui limitações inerentes ao seu processo subjetivo, tanto sob o aspecto das abordagens teóricas utilizadas, como nas suas classificações propriamente ditas. Neste artigo, adota-se a divisão proposta por Andion (2012) que, no escopo da teoria da administração pública, identificou as vertentes: estadocêntrica, pluralista, nova administração pública e novo serviço público. Nos artigos analisados alguns dos autores abordaram as correntes (veja Tabela 7), conforme citado no conteúdo do artigo. Observa-se que a corrente NSP (Novo Serviço Público) foi a mais pesquisada.

Tabela 7: Correntes estudadas nos artigos

\begin{tabular}{lc}
\hline \multicolumn{1}{c}{ Corrente } & Quantidade \\
\hline Corrente novo serviço público & 3 \\
Corrente estadocêntrica & 1 \\
Corrente pluralista & 1 \\
Corrente nova administração pública & 1 \\
\hline
\end{tabular}

Fonte: Elaborada pelos autores (2018).

No entanto, a grande maioria dos autores não abordaram correntes da teoria da administração pública, mas sim, trabalharam em seus estudos uma ou duas teorias. A Tabela 8 mostra as teorias utilizadas nos artigos, agrupadas nas correntes propostas por Andion 
(2012). Nota-se que muitas teorias não se enquadram nas correntes e que grande parte dos autores tem concentrado suas pesquisas em conceitos que não são exclusivos da administração pública, mas com discussões elaboradas a partir de teorias desenvolvidas em outros campos (FADUL; SILVA; CERQUEIRA, 2011; PACHECO, 2003; SOUZA, 1998).

Nas teorias enquadradas nas correntes, observa-se a predominância da nova administração pública e da estadocêntrica, confirmando a predominância do paradigma funcionalista apontado por Andion (2012). Assim, constata-se que para o desenvolvimento do campo em termos científicos, é necessário explorar os outros paradigmas como o interpretativo, humanista radical e estruturalista radical e suas respectivas correntes como o novo serviço público, pluralista de estudos críticos e humanistas e pluralista de estudos marxistas e neomarxistas (ANDION, 2012).

A utilização de outros paradigmas será importante para debater temas importantes para a administração pública como: a mobilização da sociedade civil e sua atuação como sujeito de mudança social e as relações entre o estado e a sociedade, considerando o estado como um espaço de luta entre as classes sociais. Essa é uma importante lacuna a ser preenchida no campo da administração pública brasileira e para isso é necessário que os trabalhos científicos considerem referenciais críticos e interpretativos.

Tabela 8: Teorias pesquisadas nos artigos

\begin{tabular}{lc}
\multicolumn{1}{c}{ Corrente estadocêntrica } & Quantidade \\
\hline Teoria da burocracia & 4 \\
Teoria da administração científica & 1 \\
Teoria do comportamento planejado & 1 \\
Teoria crítica & 3 \\
Teoria da democracia participativa & 2 \\
\hline \multicolumn{1}{c}{ Corrente da nova administração pública } & Quantidade \\
\hline Teoria institucional & 9 \\
Teoria da agência & 4 \\
Teoria da nova gestão pública & 2 \\
Teoria dos custos de transação & 2 \\
Neo-institucionalismo & 1 \\
Neo-público & 1 \\
Novo gerencialismo público & 1 \\
Novo institucionalismo & 1 \\
Teoria da escolha pública & 1 \\
Teoria da escolha racional & 1 \\
Teoria gerencial & 1 \\
\hline Teoria da coprodução & 1 \\
\hline Fonte: Elaborada pente do novo serviço público & 1 \\
\hline
\end{tabular}

Fonte: Elaborada pelos autores (2018).

\subsection{Campos/setores}

Os setores mais estudados nas publicações analisadas foram as instituições de ensino (28\%), seguido pela administração pública federal (16\%), a administração pública municipal (16\%) e as instituições de saúde (9\%) (veja Tabela 9). Esse dado revela que os estudos estão sendo realizados em instituições que os pesquisadores possuem mais vínculos 
ou maior acessibilidade. Constata-se um número menos expressivo de trabalhos em outros setores como: administração pública estadual, organizações de segurança pública, organizações sociais, instituições público-privada e tribunais. Esses setores apesar de possuírem semelhanças com os mais pesquisados, possuem também suas especificidades, sendo necessário mais estudos nessas entidades.

Tabela 9: Campos/setores estudados

\begin{tabular}{clcc}
\hline Ordem & \multicolumn{1}{c}{ Tema central } & Quantidade de artigos & $\%$ \\
\hline 1 & Instituições de ensino & 9 & $28 \%$ \\
2 & Administração pública federal & 5 & $16 \%$ \\
3 & Administração pública municipal & 5 & $16 \%$ \\
4 & Instituições de saúde & 3 & $9 \%$ \\
5 & Administração pública estadual & 2 & $6 \%$ \\
6 & Conselhos regionais & 1 & $3 \%$ \\
7 & Defensoria pública & 1 & $3 \%$ \\
9 & Incubadoras tecnológicas & 1 & $3 \%$ \\
10 & Instituições público-privada & 1 & $3 \%$ \\
11 & Organizações de segurança pública & 1 & $3 \%$ \\
12 & Organizações sociais & 1 & $3 \%$ \\
13 & Tribunal de contas & 1 & $3 \%$ \\
14 & Tribunal de justiça & 1 & $3 \%$ \\
\hline
\end{tabular}

Fonte: Elaborada pelos autores (2018).

\subsection{Procedimentos metodológicos}

Da totalidade dos artigos analisados $44 \%$ são teóricos e $56 \%$ são empíricos (veja Tabela 10). A predominância de trabalhos empíricos também foi observada por Fadul, Silva e Cerqueira (2011). Constatou-se que muitos autores não especificaram os procedimentos metodológicos em seus artigos.

Com relação à abordagem, 53\% dos artigos são qualitativos, $10 \%$ qualitativos e quantitativos e $6 \%$ quantitativos. Quanto aos procedimentos, nota-se a predominância do estudo de caso que foi utilizado por $47 \%$ dos trabalhos. O resultado encontrado está em concordância com o encontrado por Hocayen-da-Silva, Rossoni e Ferreira Júnior (2008). Em relação aos objetivos, a pesquisa descritiva prevaleceu, sendo observada em $22 \%$ dos artigos.

Os métodos de coleta mais utilizados foram dados secundários e entrevista (25\%), seguidos por trabalhos somente com dados secundários (16\%) e questionários (16\%). Apenas $9 \%$ dos trabalhos utilizaram somente entrevista. No que se refere aos métodos de análise de dados, sobressaiu a técnica de análise de conteúdo (47\%), na perspectiva qualitativa, e a análise estatística descritiva (7\%), na quantitativa.

Os resultados obtidos apontam para um delineamento de pesquisa qualitativo e descritivo, utilizando o estudo de caso como procedimento. Assim, para o enriquecimento das pesquisas no campo é necessário a diversificação dos desenhos de pesquisa, assim como dos métodos de coleta e análise de dados.

Tabela 10: Procedimentos metodológicos

Classificação quanto ao tipo de pesquisa $\quad$ Quantidade de artigos $\quad \%$




\begin{tabular}{|c|c|c|}
\hline \multirow[b]{2}{*}{ Teórico } & \\
\hline & 25 & $44 \%$ \\
\hline Empírico & 32 & $56 \%$ \\
\hline Classificação quanto à abordagem & Quantidade de artigos & $\%$ \\
\hline Qualitativa & 17 & $53 \%$ \\
\hline Quantitativa & 2 & $6 \%$ \\
\hline Qualitativa e quantitativa & 3 & $10 \%$ \\
\hline Não especificado no artigo & 10 & $31 \%$ \\
\hline Classificação quanto aos procedimentos & Quantidade de artigos & $\%$ \\
\hline Pesquisa bibliográfica & 1 & $3 \%$ \\
\hline Pesquisa documental & 1 & $3 \%$ \\
\hline Estudo de caso & 15 & $47 \%$ \\
\hline Pesquisa bibliográfica e documental & 1 & $3 \%$ \\
\hline Pesquisa bibliográfica, documental e de campo & 2 & $6 \%$ \\
\hline Não especificado no artigo & 12 & $38 \%$ \\
\hline Classificação quanto aos objetivos & Quantidade de artigos & $\%$ \\
\hline Pesquisa descritiva & 7 & $22 \%$ \\
\hline Pesquisa descritiva e explicativa & 1 & $3 \%$ \\
\hline Pesquisa explicativa & 1 & $3 \%$ \\
\hline Pesquisa exploratória & 1 & $3 \%$ \\
\hline Pesquisa exploratória e descritiva & 2 & $6 \%$ \\
\hline Não especificado no artigo & 20 & $63 \%$ \\
\hline Método de coleta de dados & Quantidade de artigos & $\%$ \\
\hline Dados secundários & 5 & $16 \%$ \\
\hline Dados secundários e entrevista & 8 & $25 \%$ \\
\hline Dados secundários e questionário & 1 & $3 \%$ \\
\hline Dados secundários, entrevista e questionário & 2 & $7 \%$ \\
\hline Dados secundários, entrevista, questionário e observação & 1 & $3 \%$ \\
\hline Dados secundários, entrevista e observação & 1 & $3 \%$ \\
\hline Entrevista & 3 & $9 \%$ \\
\hline Entrevista e observação & 1 & $3 \%$ \\
\hline Grupo de foco e entrevista & 1 & $3 \%$ \\
\hline Questionário & 5 & $16 \%$ \\
\hline Questionário, entrevista e observação & 1 & $3 \%$ \\
\hline Não especificado no artigo & 3 & $9 \%$ \\
\hline Método de análise de dados & Quantidade de artigos & $\%$ \\
\hline \multicolumn{3}{|l|}{ Análise qualitativa } \\
\hline Análise do conteúdo & 15 & $47 \%$ \\
\hline Análise do discurso & 1 & $3 \%$ \\
\hline Lógica dedutiva e indutiva & 1 & $3 \%$ \\
\hline \multicolumn{3}{|l|}{ Análise quantitativa } \\
\hline Análise de regressão múltipla & 1 & $3 \%$ \\
\hline Análise estatística descritiva & 2 & $7 \%$ \\
\hline Análise estatística descritiva e de correspondência & 1 & $3 \%$ \\
\hline Não especificado no artigo & 11 & $34 \%$ \\
\hline
\end{tabular}




\section{CONCLUSÃO}

Os resultados apresentados permitiram alcançar o objetivo geral deste estudo, que foi analisar a produção científica sobre as teorias na administração pública brasileira e responder à questão de pesquisa: como se caracteriza a produção científica na área de administração pública brasileira?

Para entender o estado da arte dessa área, faz-se necessário verificar a dinâmica de sua produção científica, o perfil dos pesquisadores, quais os temas são mais abordados, as teorias mais pesquisadas, os campos ou setores estudados e os procedimentos metodológicos adotados.

O primeiro objetivo específico foi verificar a dinâmica da produção científica no período estudado. Os resultados apontam que a produção acadêmica em teorias na administração pública brasileira cresceu no período, principalmente nos anos de 2014 e 2015, o que sugere que a área está em expansão, mesmo com queda significativa de trabalhos publicados em 2016. Sendo assim, o resultado encontrado confirma a primeira hipótese.

Em relação ao segundo objetivo específico, identificar o perfil de autoria, constatou-se que: os trabalhos analisados foram elaborados por um ou dois autores, apenas quatro autores publicaram mais de um artigo sobre o tema; a maioria dos pesquisadores são doutores e doutorandos; as instituições que possuem mais autores são a Universidade Federal de Viçosa - UFV e a Universidade Federal de Lavras - UFLA, estando localizadas no sudeste. Sendo assim, a segunda hipótese, que os pesquisadores estão concentrados nessa região, foi confirmada. Esses dados sugerem que, com relação ao perfil de autoria, não há linhas de pesquisas consolidadas nesse campo, sendo que os estudos são realizados por interesse de pesquisa pessoais dos autores, corroborando os resultados encontrados por Hocayen-da-Silva, Rossoni e Ferreira Júnior (2008).

O terceiro objetivo específico foi identificar os temas mais abordados. Esses em ordem decrescente foram: gestão pública, gestão social, inovação, análise organizacional, epistemologia e políticas públicas. A terceira hipótese era que os temas mais abordados seriam sobre análise organizacional. Ela não foi confirmada, visto que os de maior frequência foram gestão pública e gestão social. No entanto, a análise organizacional figura entre os quatro mais relevantes. É importante destacar a forma abrangente como o tema gestão pública tem sido tratado e a importância de pesquisas mais específicas, além do estudo de outras matérias pertinentes como relações internacionais, crise do estrado, transparência, etc.

O quarto objetivo específico foi identificar as teorias mais pesquisadas. Foi constatado que as teorias mais utilizadas são aquelas que pertencem à corrente da nova administração pública, confirmando a quarta hipótese. Essa corrente vincula-se ao paradigma funcionalista predominante no campo, conforme apontado por Andion (2012). Dessa forma, para o desenvolvimento do campo, faz-se necessário explorar os outros paradigmas (interpretativo, humanista radical e estruturalista radical) e suas respectivas correntes. A utilização desses paradigmas não funcionalistas será importante para debater temas emergentes na administração pública como: mobilização da sociedade civil, relações entre estado e sociedade, conflito e subjetividade de atores políticos.

O quinto objetivo específico foi identificar os campos/setores mais estudados. As instituições de ensino, a administração pública federal, a administração pública municipal e as instituições de saúde foram os principais setores analisados. Sendo assim, a quinta 
hipótese, que o setor mais estudado envolve as universidades, foi confirmada. Constata-se a necessidade de realizar pesquisa em outros setores públicos como tribunais, organizações sociais, organizações de segurança pública, etc. que possuem características diferentes dos setores mais estudados.

Por fim, o sexto objetivo específico foi identificar os procedimentos metodológicos adotados. Predominam as pesquisas empíricas, de abordagem qualitativa e de natureza descritiva; o procedimento mais adotado foi o estudo de caso; os métodos de coleta de dados mais utilizados foram dados secundários e entrevista; e a técnica de análise de dados mais utilizada foi a de conteúdo. De acordo com esses resultados, confirma-se a sexta hipótese, que sugeria que as pesquisas desenvolvidas nessa área tinham predominância da abordagem qualitativa, de natureza descritiva e como procedimento estudo de caso. Sugere-se que para a evolução do campo sejam realizadas pesquisas com outros delineamentos, diversificando a abordagem, métodos de coleta e análise de dados.

O presente estudo contribui para o campo da administração pública brasileira, fornecendo dados que poderão ser utilizados para nortear trabalhos acerca de suas teorias. Como limitação desta pesquisa, aponta-se o pequeno número de estudos acadêmicos sobre teorias na administração pública, encontrados na base de dados SPELL (Scientific Periodicals Eletronic Library). Recomenda-se replicar esta pesquisa com outra base de dados de periódicos, como o portal CAPES, bem como realizar estudos qualitativos com o objetivo de aprofundar a compreensão das teorias e dos paradigmas a que estão vinculados.

\section{REFERÊNCIAS}

ACEVEDO, Claudia Rosa; NOHARA, Jouliana Jordan. Monografia no curso de Administração: guia completo de conteúdo e forma. 2. ed. São Paulo: Atlas, 2006.

AKIM, Érica Kushihara; MERGULHÃO, Ricardo Coser. Panorama da produção intelectual sobre a medição de desempenho na gestão pública. Revista de Administração Pública, Rio de Janeiro, v. 49, n.2, p. 337-366, mar./abr. 2015.

ANDION, Carolina. Por uma nova interpretação das mudanças de paradigma na administração pública. Cadernos EBAPE.BR, v. 10, n. 1, p. 1-19, mar. 2012.

ARAÚJO JÚNIOR, José Alves; MARTINS, Igor. Gestão por competências na administração pública: uma análise bibliométrica a partir do decreto lei 5.707/2006. Revista Gestão.Org, v. 12, n. 2, p. 153-162. 2014.

CARDOSO, Ricardo Lopes; MENDONÇA NETO, Octávio Ribeiro de; RICCIO, Edson Luiz; SAKATA, Marici Cristine Gramacho. Pesquisa científica em contabilidade entre 1990 e 2003. Revista de Administração de Empresas, v. 45, n. 2, p.34-45, abr./jun. 2005.

CHIZZOTTI, Antonio. Análise de conteúdo, análise de narrativa, análise do discurso. In: . (Org.). Pesquisa qualitativa em ciências humanas e sociais. 4. ed., Petrópolis, RJ: Vozes, 2006, p. 113-134.

COELHO, Fernando de Souza; NICOLINI, Alexandre Mendes. Uma contribuição à história do ensino de graduação em Administração Pública no Brasil (1952 -1994): proposta de 
periodização e análise de um dos estágios de construção. In: ENCONTRO DA ASSOCIAÇÃO NACIONAL DOS PROGRAMAS DE PÓS-GRADUAÇÃO EM ADMINISTRAÇÃO, 34., 2010, Rio de Janeiro. Anais... Rio de Janeiro: Anpad, 2010. p. 1-17.

FADUL, Élvia; SILVA, Lindomar Pinto da; CERQUEIRA, Lucas Santos. Análise do campo da administração pública através da produção científica publicada nos anais dos EnAPGs. Cadernos Gestão Pública e Cidadania, São Paulo, v. 16, n. 59, p. 151-166, jul./dez. 2011.

GUEDES, Vania Lisboa da Silveira; BORSCHIVER, Suzana. Bibliometria: uma ferramenta estatística para a gestão da informação e do conhecimento, em sistemas de informação, de comunicação e de avaliação científica e tecnológica. In: ENCONTRO NACIONAL DE CIÊNCIA DA INFORMAÇÃO, 6., 2005, Salvador. Anais... Salvador, 2005. p. 1-18.

HOCAYEN-DA-SILVA, Antônio João; ROSSONI, Luciano; FERREIRA JÚNIOR, Israel. Administração pública e gestão social: a produção científica brasileira entre 2000 e 2005. Revista de Administração Pública, Rio de Janeiro, v. 42, n. 4, p. 655-80, jul./ago. 2008.

KEINERT, Tania Margarete Mezzomo. Administração pública no Brasil: crises e mudanças de paradigmas. 2. ed. São Paulo: Annablume: Fapesp, 2007.

KEINERT, Tania Margarete Mezzomo. Os paradigmas da administração pública no Brasil (1900-1992). Revista de Administração de Empresas, v. 34, n. 3, p.41-48, mai./jun. 1994.

KEINERT, Tania Margarete Mezzomo; VAZ, José Carlos. Histórico da RSP: a Revista do Serviço Público no pensamento administrativo brasileiro (1937-1989). Revista do Serviço Público, v. 118, n. 45, p. 9-42, 1994.

LOCKE, Lawrence F.; SILVERMAN, Stephen J.; SPIRDUSO, Waneen Wyrick. Reading and understanding research. 3. ed. SAGE Publications. 2010.

MACIAS-CHAPULA, Cesar A. O papel da informetria e da cienciometria e sua perspectiva nacional e internacional. Ciência da Informação, v. 27, n. 2, p. 134-140, mai./ago. 1998.

MATOS, Osvair Almeida; VENÂNCIO, Daniella Macedo; DUTRA, Ademar. Gestão estratégica em instituições de ensino superior: mapeamento das publicações científicas no período de 1997 a 2012. Revista GUAL, Florianópolis, v. 7, n. 1, p. 106-127, jan. 2014.

MEZZOMO, Tânia Margarete; LAPORTA, Claudio Bucci. A RAP e a evolução do campo de administração pública no Brasil (1965-92). Revista de Administração Pública, Rio de Janeiro, v. 28, n. 1, p. 5-17, jan./mar. 1994.

MORGAN, Gareth. Paradigmas, metáforas e resolução de quebra-cabeças na teoria das organizações. In: CALDAS, Miguel; BERTERO, Carlos. Teoria das Organizações. Série ERA Clássicos. São Paulo: FGV/RAE/Atlas, 2007. 
OTLET, Paul. O livro e a medida bibliometria. In: FONSECA, Edson Nery da. (Org.).

Bibliometria: teoria e prática. 1. ed. São Paulo: Cultrix: Editora da Universidade de São Paulo, 1986. p. 19-34.

PACHECO, Regina Silvia. Administração pública nas revistas especializadas - Brasil, 19952002. Revista de Administração Eletrônica, v. 43, n. 4, p. 63-71, out./dez. 2003.

PIRES, Valdemir; MIDLEJ E SILVA, Suylan de A.; SILVA, Sérgio Azevedo; VENDRAMINI, Patrícia; COELHO, Fernando Souza. Dossiê - Campo de Públicas no Brasil: definição, movimento constitutivo e desafios atuais. Administração Pública e Gestão Social, v. 6, n. 3, p. 110-126, jul./set. 2014.

RIBEIRO, Henrique César Melo. Doze anos de estudo da Revista de Administração Pública à luz da bibliometria e da rede social. Revista Ciências Administrativas, Fortaleza, v. 20, n. 1, p. 137-167, jan./jun. 2014.

SAMPIERI, Roberto Hernández; COLLADO, Carlos Fernández; LUCIO, Pilar Baptista. Metodologia de pesquisa. 5. ed. São Paulo: McGraw-Hill, 2013.

SOUZA, Celina. Pesquisa em administração pública no Brasil: uma agenda para o debate. Revista de Administração Pública, Rio de Janeiro, v. 32, n.4, p. 43-61, jul./ago. 1998.

VENDRAMINI, Patrícia. Ensino de administração pública e o desenvolvimento de competências: a contribuição do Curso de Administração Pública da ESAG-UDESC. 2013. 262 f. Tese (Doutorado em Administração) - Núcleo de Pós-Graduação em Administração, Universidade Federal da Bahia, Salvador, 2013. 


\section{APÊNDICE - LISTA DOS ARTIGOS PESQUISADOS DA AMOSTRA}

\begin{tabular}{|c|c|c|c|}
\hline № & Autores (ano) & Título do artigo & Identificação da Revista \\
\hline 01 & Andrade (2006) & $\begin{array}{l}\text { Redes de atores: uma nova forma de } \\
\text { gestão das políticas públicas no } \\
\text { Brasil? }\end{array}$ & Gestão \& Regionalidade \\
\hline 02 & Gomes (2006) & $\begin{array}{l}\text { Stakeholder management in the local } \\
\text { government decision-making area: } \\
\text { evidences from a triangulation study } \\
\text { with the English local government }\end{array}$ & $\begin{array}{l}\text { Revista de Administração } \\
\text { Contemporânea }\end{array}$ \\
\hline 03 & Predebon e Sousa (2006) & $\begin{array}{l}\text { The feasibility of grounded theory } \\
\text { methodology on Brazilian public } \\
\text { administration research }\end{array}$ & $\begin{array}{l}\text { Revista de Administração da } \\
\text { UNIMEP }\end{array}$ \\
\hline 04 & Oliveira e Rezende (2007) & $\begin{array}{l}\text { Análise das variáveis culturais da } \\
\text { gestão municipal sob a óptica da } \\
\text { nova gestão pública }\end{array}$ & Revista de Negócios \\
\hline 05 & Peres (2007) & $\begin{array}{l}\text { Custos de transação e estrutura de } \\
\text { governança no setor público }\end{array}$ & $\begin{array}{l}\text { Revista Brasileira de Gestão de } \\
\text { Negócios }\end{array}$ \\
\hline 06 & Guedes e Faria (2007) & $\begin{array}{l}\text { Globalization and international } \\
\text { management: in search of an } \\
\text { interdisciplinary approach }\end{array}$ & Brazilian Administration Review \\
\hline 07 & Araújo (2008) & $\begin{array}{l}\text { Breves considerações sobre a crise do } \\
\text { Estado e orientações teóricas para } \\
\text { sua reforma }\end{array}$ & $\begin{array}{l}\text { Interface - Revista do Centro de } \\
\text { Ciências Sociais Aplicadas }\end{array}$ \\
\hline 08 & Pinto (2008) & $\begin{array}{l}\text { Construção da agenda } \\
\text { governamental: atores, arenas e } \\
\text { processo decisório na saúde }\end{array}$ & Organizações \& Sociedade \\
\hline 09 & Salm e Menegasso (2009) & $\begin{array}{l}\text { Os modelos de administração pública } \\
\text { como estratégias complementares } \\
\text { para a coprodução do bem público }\end{array}$ & $\begin{array}{l}\text { Revista de Ciências da } \\
\text { Administração }\end{array}$ \\
\hline 10 & Carvalho et al. (2010) & $\begin{array}{l}\text { A universidade como (re)produtora } \\
\text { de estruturas de significados: uma } \\
\text { análise semiótica institucional }\end{array}$ & Revista ADM.MADE \\
\hline 11 & Faria et al. (2010) & $\begin{array}{l}\text { Aspectos transacionais e } \\
\text { comportamentais dos agentes no } \\
\text { pregão eletrônico: um enfoque na } \\
\text { administração pública }\end{array}$ & $\begin{array}{l}\text { Revista de Economia e } \\
\text { Administração }\end{array}$ \\
\hline 12 & Abreu e Gomes (2010) & $\begin{array}{l}\text { Orçamento público: análise da } \\
\text { formulação de estratégias sob a } \\
\text { perspectiva do planejamento } \\
\text { emancipatório e desenvolvimentista }\end{array}$ & Revista do Serviço Público \\
\hline 13 & Andrade (2011) & $\begin{array}{l}\text { Formação estratégica: as políticas } \\
\text { públicas a partir das práticas }\end{array}$ & $\begin{array}{l}\text { Revista Eletrônica de Ciência } \\
\text { Administrativa }\end{array}$ \\
\hline 14 & Allebrandt et al. (2011) & $\begin{array}{l}\text { Gestão social e cidadania } \\
\text { deliberativa: uma análise da } \\
\text { experiência dos Coredes no Rio } \\
\text { Grande do Sul, 1990- } 2010\end{array}$ & Cadernos EBAPE.BR \\
\hline 15 & Rosa e Mendonça (2011) & $\begin{array}{l}\text { Movimentos sociais e análise } \\
\text { organizacional: explorando } \\
\text { possibilidades a partir da teoria de } \\
\text { frames e a de oportunidades } \\
\text { políticas. }\end{array}$ & Organizações \& Sociedade \\
\hline 16 & $\begin{array}{l}\text { Baeta, Mucci e Moreira } \\
(2011)\end{array}$ & $\begin{array}{l}\text { O institucionalismo sociológico na } \\
\text { implementação da política e atenção }\end{array}$ & $\begin{array}{l}\text { Administração Pública e Gestão } \\
\text { Social }\end{array}$ \\
\hline
\end{tabular}




\begin{tabular}{|c|c|c|c|}
\hline & & $\begin{array}{l}\text { à saúde do servidor público de uma } \\
\text { instituição federal de ensino superior } \\
\text { de Minas Gerais }\end{array}$ & \\
\hline 17 & Assis e Reis Neto (2011) & $\begin{array}{l}\text { Remuneração variável no setor } \\
\text { público: investigação das causas do } \\
\text { fracasso e implicações para o Estado } \\
\text { Brasileiro }\end{array}$ & $\begin{array}{l}\text { GESTÃO.Org - Revista Eletrônica } \\
\text { de Gestão Organizacional }\end{array}$ \\
\hline 18 & Zwick et al. (2012) & $\begin{array}{l}\text { Administração pública tupiniquim: } \\
\text { reflexões a partir da Teoria N e da } \\
\text { Teoria P de Guerreiro Ramos }\end{array}$ & Cadernos EBAPE.BR \\
\hline 19 & $\begin{array}{l}\text { Rodrigues e Souza Neto } \\
\text { (2012) }\end{array}$ & $\begin{array}{l}\text { Diretrizes para implantação da } \\
\text { governança de tecnologia da } \\
\text { informação no setor público } \\
\text { brasileiro à luz da teoria institucional }\end{array}$ & Revista do Serviço Público \\
\hline 20 & Monteiro (2012) & $\begin{array}{l}\text { Ensaio - A ideologia da modernização } \\
\text { burocrática e seu papel na } \\
\text { implantação do Estado nacional } \\
\text { desenvolvimentista brasileiro }\end{array}$ & $\begin{array}{l}\text { Revista Capital Científico - } \\
\text { Eletrônica }\end{array}$ \\
\hline 21 & $\begin{array}{l}\text { Silva, Pereira e Alcântara } \\
\text { (2012) }\end{array}$ & $\begin{array}{l}\text { Interfaces epistemológicas sobre } \\
\text { administração pública, } \\
\text { institucionalismo e capital social }\end{array}$ & Cadernos EBAPE.BR \\
\hline 22 & Silva e Melo (2012) & $\begin{array}{l}\text { Os reflexos de práticas } \\
\text { socioambientais organizacionais } \\
\text { sobre as atitudes individuais: uma } \\
\text { compreensão à luz da teoria do } \\
\text { comportamento planejado }\end{array}$ & $\begin{array}{l}\text { Revista Capital Científico - } \\
\text { Eletrônica }\end{array}$ \\
\hline 23 & Andion (2012) & $\begin{array}{l}\text { Por uma nova interpretação das } \\
\text { mudanças de paradigma na } \\
\text { administração pública }\end{array}$ & Cadernos EBAPE.BR \\
\hline 24 & Fraga e Souza (2012) & $\begin{array}{l}\text { Uma nova visão da análise dos atos } \\
\text { de aposentadoria a cargo do TCE/RJ: } \\
\text { um caso de ensaio de custos para } \\
\text { retorno socioeconômico }\end{array}$ & $\begin{array}{l}\text { Revista de Administração } \\
\text { Pública }\end{array}$ \\
\hline 25 & $\begin{array}{l}\text { Peres Jr., Pereira e Oliveira } \\
(2013)\end{array}$ & $\begin{array}{l}\text { Gestão social sob a lente } \\
\text { estruturacionista }\end{array}$ & $\begin{array}{l}\text { Revista de Administração } \\
\text { Mackenzie }\end{array}$ \\
\hline 26 & $\begin{array}{l}\text { Abreu, Helou e Fialho } \\
\text { (2013) }\end{array}$ & $\begin{array}{l}\text { Possibilidades epistemológicas para a } \\
\text { ampliação da teoria da administração } \\
\text { pública: uma análise a partir do } \\
\text { conceito do Novo Serviço Público }\end{array}$ & Cadernos EBAPE.BR \\
\hline 27 & $\begin{array}{l}\text { Justen e Moretto Neto } \\
\text { (2013) }\end{array}$ & $\begin{array}{l}\text { Que participação é essa? Do } \\
\text { instrumentalismo legitimador à } \\
\text { autopromoção emancipadora }\end{array}$ & Pensamento \& Realidade \\
\hline 28 & Queiroz et al. (2013) & $\begin{array}{l}\text { Transparência dos municípios do Rio } \\
\text { Grande do Norte: avaliação da } \\
\text { relação entre o nível de disclosure, } \\
\text { tamanho e características } \\
\text { socioeconômicas }\end{array}$ & $\begin{array}{l}\text { Revista Evidenciação Contábil \& } \\
\text { Finanças }\end{array}$ \\
\hline 29 & Vidal (2013) & $\begin{array}{l}\text { Uma observação autorreferencial na } \\
\text { Defensoria Pública do Estado do Pará }\end{array}$ & $\begin{array}{l}\text { Amazônia, Organizações e } \\
\text { Sustentabilidade }\end{array}$ \\
\hline 30 & Borges e Pereira (2014) & $\begin{array}{l}\text { Educação fiscal e eficiência pública: } \\
\text { um estudo das suas relações a partir } \\
\text { da gestão de recursos municipais }\end{array}$ & $\begin{array}{l}\text { Revista de Educação e Pesquisa } \\
\text { em Contabilidade }\end{array}$ \\
\hline 31 & Mattia e Zappelline (2014) & $\begin{array}{l}\text { Ética e coprodução de serviços } \\
\text { públicos: uma fundamentação a } \\
\text { partir de Habermas }\end{array}$ & Cadernos EBAPE.BR \\
\hline 32 & Gomes (2014) & Ética na administração pública: & Revista de Administração \\
\hline
\end{tabular}




\begin{tabular}{|c|c|c|c|}
\hline & & desafios e possibilidades & Pública \\
\hline 33 & Garrido e Justen (2014) & $\begin{array}{l}\text { Incubadoras de gestão social e gestão } \\
\text { universitária: possibilidades e } \\
\text { contribuições a partir de análise } \\
\text { comparativa }\end{array}$ & $\begin{array}{l}\text { Amazônia, Organizações e } \\
\text { Sustentabilidade }\end{array}$ \\
\hline 34 & Freitas e Dacorso (2014) & $\begin{array}{l}\text { Inovação aberta na gestão pública: } \\
\text { análise do plano de ação brasileiro } \\
\text { para a Open Government Partnership }\end{array}$ & $\begin{array}{l}\text { Revista de Administração } \\
\text { Pública }\end{array}$ \\
\hline 35 & Pimentel (2014) & $\begin{array}{l}\text { O espaço em situações de gestão: } \\
\text { entre a gestão estratégica e a gestão } \\
\text { social }\end{array}$ & $\begin{array}{l}\text { Administração Pública e Gestão } \\
\text { Social }\end{array}$ \\
\hline 36 & Novaes e Santos (2014) & $\begin{array}{l}\text { O orçamento participativo e a } \\
\text { democratização da gestão pública } \\
\text { municipal - a experiência de Vitória } \\
\text { da Conquista (BA) }\end{array}$ & $\begin{array}{l}\text { Revista de Administração } \\
\text { Pública }\end{array}$ \\
\hline 37 & $\begin{array}{l}\text { Daniel, Pereira e Macadar } \\
\text { (2014) }\end{array}$ & $\begin{array}{l}\text { Perspectiva institucional dos sistemas } \\
\text { de informação em saúde em dois } \\
\text { estados brasileiros }\end{array}$ & $\begin{array}{l}\text { Revista de Administração } \\
\text { Contemporânea }\end{array}$ \\
\hline 38 & $\begin{array}{l}\text { Alves, Castro e Souto } \\
(2014)\end{array}$ & $\begin{array}{l}\text { Processo de institucionalização do } \\
\text { curso de graduação em } \\
\text { Administração Pública a distância da } \\
\text { Universidade Federal }\end{array}$ & $\begin{array}{l}\text { Revista de Administração } \\
\text { Contemporânea }\end{array}$ \\
\hline 39 & Lima e Vargas (2014) & $\begin{array}{l}\text { Regulação de acesso à internação em } \\
\text { UTI: análise pela teoria da inovação } \\
\text { em serviços }\end{array}$ & $\begin{array}{l}\text { Revista de Administração } \\
\text { Hospitalar e Inovação em Saúde }\end{array}$ \\
\hline 40 & Carvalho (2015) & $\begin{array}{l}\text { "Juntos Faremos": deliberação como } \\
\text { alternativa de gestão na } \\
\text { Administração Pública }\end{array}$ & $\begin{array}{l}\text { Administração Pública e Gestão } \\
\text { Social }\end{array}$ \\
\hline 41 & Monje-Reyes (2015) & $\begin{array}{l}\text { A teoria crítica como perspectiva de } \\
\text { análise das relações de dominação e } \\
\text { dos processos de descentralização no } \\
\text { Chile }\end{array}$ & Cadernos EBAPE.BR \\
\hline 42 & Oliveira (2015) & $\begin{array}{l}\text { Análise de correspondência aplicada } \\
\text { a preposições sobre a eficiência e } \\
\text { eficácia do processo de compras } \\
\text { públicas a partir da percepção de } \\
\text { diferentes atores envolvidos }\end{array}$ & Revista Ciências Administrativas \\
\hline 43 & Pinho e Santos (2015) & $\begin{array}{l}\text { Aporias em torno do conceito de } \\
\text { Gestão Social: dilemas teóricos e } \\
\text { políticos }\end{array}$ & Revista de Gestão \\
\hline 44 & Romão Netto (2015) & $\begin{array}{l}\text { Gestão de políticas de cultura e } \\
\text { qualidade da democracia: São Paulo, } \\
10 \text { anos de um modelo ainda em } \\
\text { construção }\end{array}$ & $\begin{array}{l}\text { Revista de Administração } \\
\text { Pública }\end{array}$ \\
\hline 45 & Cahen (2015) & $\begin{array}{l}\text { Internacionalização de empresas } \\
\text { estatais através de investimento } \\
\text { direto estrangeiro }\end{array}$ & $\begin{array}{l}\text { Revista de Administração de } \\
\text { Empresas }\end{array}$ \\
\hline 46 & Oliveira et al. (2015) & $\begin{array}{l}\text { Leaderships in urban contexts of } \\
\text { diversity and innovation: the Porto } \\
\text { Maravilha Case }\end{array}$ & Brazilian Administration Review \\
\hline 47 & Freitas e Medeiros (2015) & $\begin{array}{l}\text { Organizational impacts of the } \\
\text { electronic processing system of the } \\
\text { Brazilian superior court of justice }\end{array}$ & $\begin{array}{l}\text { Journal of Information Systems } \\
\text { and Technology Management }\end{array}$ \\
\hline 48 & $\begin{array}{l}\text { Fonseca, Pereira e } \\
\text { Gonçalves (2015) }\end{array}$ & $\begin{array}{l}\text { Retórica na construção de realidades } \\
\text { na segurança pública: abordagens } \\
\text { dos sistemas de Minas Gerais e São }\end{array}$ & $\begin{array}{l}\text { Revista de Administração } \\
\text { Pública }\end{array}$ \\
\hline
\end{tabular}




\begin{tabular}{|c|c|c|c|}
\hline & & Paulo & \\
\hline 49 & Sousa et al. (2015) & $\begin{array}{l}\text { Retratando a inovação no serviço } \\
\text { público brasileiro: modelos de } \\
\text { análise, sistematização e } \\
\text { caracterização }\end{array}$ & Revista de Administração \\
\hline 50 & Bairral, Silva e Alves (2015) & $\begin{array}{l}\text { Transparência no setor público: uma } \\
\text { análise dos relatórios de gestão } \\
\text { anuais de entidades públicas federais } \\
\text { no ano de } 2010\end{array}$ & $\begin{array}{l}\text { Revista de Administração } \\
\text { Pública }\end{array}$ \\
\hline 51 & Cintra et al. (2015) & $\begin{array}{l}\text { Turismo local de Londrina-PR: análise } \\
\text { a partir da teoria do stakeholder }\end{array}$ & $\begin{array}{l}\text { Contextus - Revista } \\
\text { Contemporânea de Economia e } \\
\text { Gestão }\end{array}$ \\
\hline 52 & $\begin{array}{l}\text { Versiane, Rezende e } \\
\text { Pereira (2016) }\end{array}$ & $\begin{array}{l}\text { Contribuições da teoria institucional } \\
\text { para a análise da gestão de escolas: } \\
\text { um estudo de caso de escola pública } \\
\text { brasileira bem sucedida nos índices } \\
\text { de desempenho da educação básica }\end{array}$ & $\begin{array}{l}\text { Revista Eletrônica de } \\
\text { Administração }\end{array}$ \\
\hline 53 & Ferreira e Prando (2016) & $\begin{array}{l}\text { Diagnosticando a disfunção } \\
\text { burocrática do papelório: o desafio } \\
\text { da eficiência na gestão pública (o } \\
\text { caso de uma autarquia federal) }\end{array}$ & Desafio Online \\
\hline 54 & $\begin{array}{l}\text { Cintra, Amâncio-Vieira e } \\
\text { Munck (2017) }\end{array}$ & $\begin{array}{l}\text { A produção intelectual em teoria } \\
\text { institucional: análise nos principais } \\
\text { periódicos brasileiros a partir do } \\
\text { método bibliométrico }\end{array}$ & $\begin{array}{l}\text { Future Studies Research } \\
\text { Journal: Trends and Strategies }\end{array}$ \\
\hline 55 & Valadares et al. (2017) & $\begin{array}{l}\text { Administração pública sob a ótica dos } \\
\text { estudos críticos: reflexões, } \\
\text { interlocuções e tendências }\end{array}$ & $\begin{array}{l}\text { Administração Pública e Gestão } \\
\text { Social }\end{array}$ \\
\hline 56 & Gonzaga (2017) & $\begin{array}{l}\text { Avaliação de desempenho no } \\
\text { governo mineiro: alterações dos } \\
\text { indicadores e metas }\end{array}$ & $\begin{array}{l}\text { Revista de Administração } \\
\text { Contemporânea }\end{array}$ \\
\hline 57 & Schmitt e Bier (2017) & $\begin{array}{l}\text { Gestão de níveis de serviços: um } \\
\text { instrumento para aprimorar as } \\
\text { contratações da administração } \\
\text { pública estadual e municipal }\end{array}$ & $\begin{array}{l}\text { RACE: Revista de } \\
\text { Administração, Contabilidade e } \\
\text { Economia }\end{array}$ \\
\hline 58 & Reis (2017) & $\begin{array}{l}\text { Modelo orçamentário das } \\
\text { universidades federais: fatores } \\
\text { motivadores e inibidores de sua } \\
\text { institucionalização }\end{array}$ & $\begin{array}{l}\text { Revista de Administração da } \\
\text { UFSM }\end{array}$ \\
\hline
\end{tabular}

Fonte: Elaborada pelos autores (2018). 